\title{
Time Trend of Mortality from Esophagus Cancer During 2005-2014 in the Nghe An Province, Viet Nam
}

\author{
Kim Cat Tuyen Vo ${ }^{1 *}$, Dao Viet Hang ${ }^{2,3,4}$, Dao Van Long ${ }^{2,3,4}$, Hoang Bao Long ${ }^{4}$, Lam Ngoc Hoa ${ }^{4}$, \\ Nguyen Van Thuong ${ }^{5}$ and Le Tran Ngoan ${ }^{6,7}$ \\ ${ }^{1}$ Graduate School of Medicine, International University of Health and Welfare, Japan \\ 2Hanoi Medical University, Viet Nam \\ ${ }^{3}$ Hanoi Medical University Hospital, Viet Nam \\ ${ }^{4}$ Institute of Gastroenterology and Hepatology, Viet Nam \\ ${ }^{5}$ Department of Health Nghe An province, Viet Nam \\ ${ }^{6}$ Institute of Research and Development, Duy Tan University, Viet Nam \\ ${ }^{7}$ Department of Public Health, School of Medicine, International University of Health and Welfare, Japan \\ *Corresponding author: Kim Cat Tuyen Vo, Graduate School of Medicine, International University of Health and Welfare, Narita, \\ Japan
}

\section{ARTICLE INFO}

Received: 慧 December 17, 2021

Published: 幽 January 11, 2022

Citation: Kim Cat Tuyen Vo, Dao Viet Hang, Dao Van Long, Hoang Bao Long, Lam Ngoc Hoa, et al., Time Trend of Mortality from Esophagus Cancer During 2005-2014 in the Nghe An Province, Viet Nam. Biomed J Sci \& Tech Res 40(5)2022. BJSTR. MS.ID.006524.

Abbreviations: EC: Esophageal Cancer; HDI: Human Development Index; SHS: State Health Stations; ALDH2: Aldehyde Dehydrogenase 2; MRR: Mortality Rates Ratio; CI: Confidence Interval

\section{ABSTRACT}

Objectives: To describe the time trend of esophageal cancer (EC) mortality that occurred in Nghe An province during 2005-2014.

Methods: Mortality due to EC and all causes were annually collected from the A6 death register system using the "Validated mortality registration forms" from 2005 to 2014 . There was a mandatory monthly active mortality registration by 480 state health stations following the A6 death register system. Age-standardized rates (ASR) of mortality and mortality rate ratio and $95 \%$ confidence interval (MRR (95\%CI)) by time-period were estimated.

Results: Among 140,670 reported deaths, 639 were due to EC (Men 527, women 112). The mortality rate (WHO-ASR) per 100,000 was 4.70 in men and 0.77 in women, giving the men to women ratio was 6.1. Mortality from EC was significantly increased during the 10 years, 2013-2014 vs. 2005-2006, MRR (95\%CI): 2.79 (1.95, 3.99), p for trend $<0.05$.

Conclusion: We observed an increased time trend of mortality due to EC; men are responsible for over $80 \%$ of this fatal disease, therefore, a program of primary and secondary prevention against EC focused on men is highly needed in the Nghe An province.

Keywords: Esophagus; Cancer; Time-Trend; Mortality

\section{Introduction}

Esophageal cancer (EC) is the seventh most common malignancy with 572,034 (3.2\%) new cases in 2018. EC ranked sixth in mortality with 505,585 cases in 2018 , accounting for
$5.3 \%$ of total cancer deaths. According to GLOBOCAN 2018, more than $75 \%$ of death from EC occurred in Asia, mainly in developing countries $[1,2]$. The prognosis of EC is poor with the 5 -year relative 
survival rate ranging from $4-40 \%$ depending on the stages of cancer. The five-year survival rate was less than $20 \%$ [3]. Although the incidence and mortality rate of EC did not increase significantly in the past, EC is expected to be a global burden in the future. The main reasons are the transition of age structure and the increasing proportion of people with harmful alcohol consumption, smoking, obesity, and low fruit and vegetable intake [4,5]. Viet Nam has an average human development index (HDI) and is facing a double burden of both communicable and non-communicable diseases. In Viet Nam, non-communicable diseases are responsible for about $68 \%$ of the disease burden and are the leading cause of death (accounting for $77 \%$ of total deaths) [6,7]. According to GLOBOCAN 2018, Viet Nam reported 2,411 new cases and 2,222 deaths from EC (accounting for 1.9\% of all cancer deaths) [8]. Data in Viet Nam on mortality from all cancers combined and from EC were limited. We conducted this study to describe the time trend of EC mortality in Nghe An province from 2005 to 2014.

\section{Methods}

Nghe An province has a total area of $16,493.7 \mathrm{~km}^{2}$ and is located in the North Central Region. Nghe An is bordered to the East by the sea, to the West by Laos, to the North by Thanh Hoa province, and to the South by Ha Tinh province (Figure 1). Nghe An has 21 districts, cities, towns, and 480 state health stations with a population of 3,215,179 in 2009. The descriptive epidemiological method was used to conduct the study. Mortality due to EC and all causes were annually collected from the A6 death register system using the "Validated mortality registration forms" from 2005 to 2014. There was a mandatory monthly active mortality registration by 480 state health stations (SHS) following the A6 death register system. Deaths recorded in the family register management system of Nghe An (regardless of location) from January 1, 2005, to December 31, 2014, were indexed in the A6 records of 480 SHS in 21 districts/town/cities. We excluded deaths that occurred in the study area but were not recorded in the family registry of Nghe An. For each reported death, the investigators annually collected the patient's information (name, age, gender, date of death, and cause of death assigned by ICD-10 code) and filled in the printed form of "Validated mortality registration forms". During the 10 years, our study collected 140,670 deaths, of which 639 were deaths from EC. In 2014, the list of deaths from the A6 death register system was validated by the Verbal Autopsy instrument. The quality of mortality from cancer in general and EC, in particular, was very good regarding accuracy and completeness. The data were checked, cleaned, encrypted, and then entered using Excel software. Deaths from EC (C15) were selected. We used STATA 10 analysis software to calculate the age-standardized mortality rate per 100,000 persons by using 3 standard populations: Segi World Standard; European standard; WHO World Standard (2000-2025).

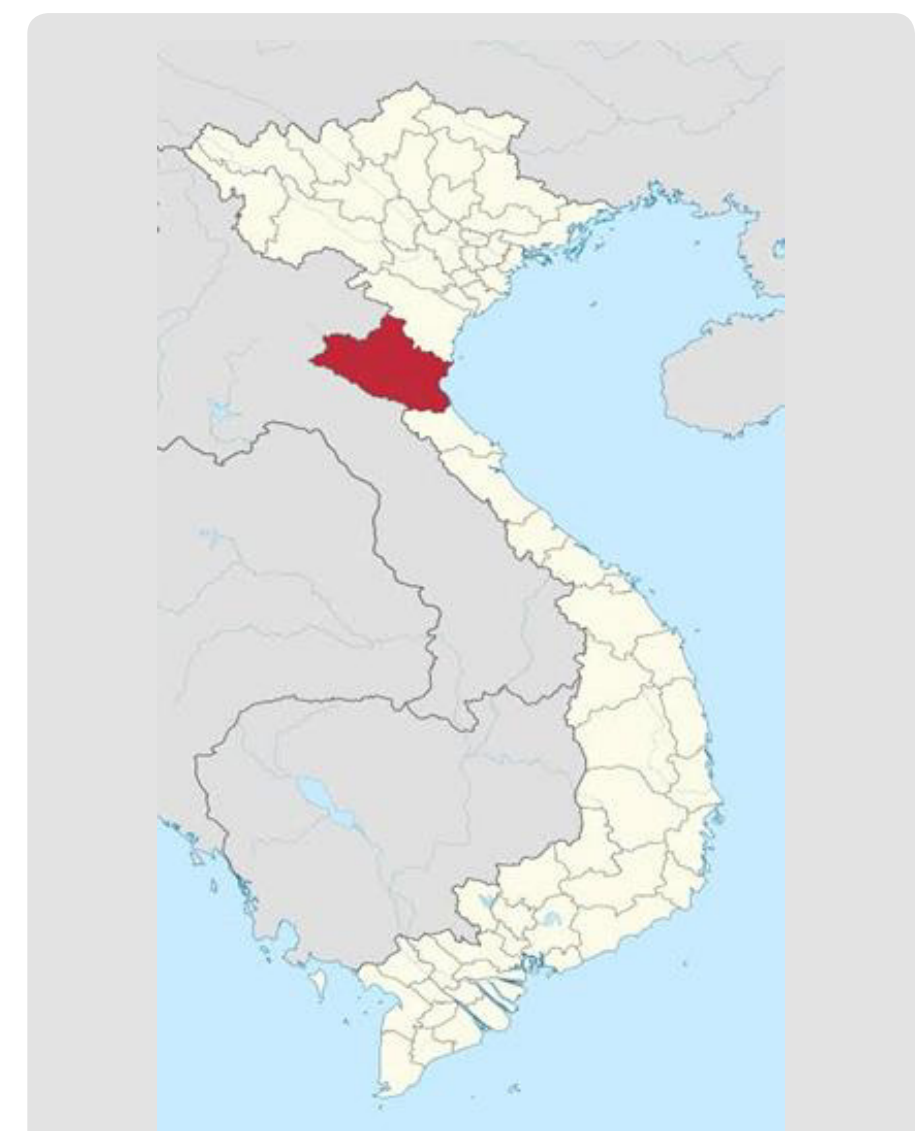

Figure 1: Location of Nghe An province in Viet Nam.

We used the following equation to calculate the agestandardized mortality rate:

$\sum_{i} d_{i} w_{i} / y_{i}$

$\mathrm{d}_{\mathrm{i}}$ : number of deaths in the $\mathrm{i}^{\text {th }}$ age group,

$\mathrm{w}_{\mathrm{i}}$ : population in the $\mathrm{i}^{\text {th }}$ age group of the standard population,

$Y_{i}$ : person-years in the $i^{\text {th }}$ age group $[9,10]$.

Mortality rates ratio and 95\% confidence interval (MRR, 95\% CI) was estimated by performing logistic regression analysis to examine time trends and risk of deaths due to EC, adjusted for sex, age, the proportion of unknown underlying cause of death, and allcause mortality rates by time. For time trends during 2005-2014, we divided into five periods of 2005-2006 (the reference group), 2007-2008, 2009-2010, 2011-2012, and 2013-2014. The research protocol was approved by the Ethics Committee of Hanoi Medical University on Nov. 25, 2008. The study was conducted under the approval of local authorities and health authorities in the study area. The collected information was completely confidential and only used for scientific purposes. 


\section{Results}

The total number of deaths from EC in Nghe An from 2005 to 2014 was 639 out of 140,670 reported deaths; 527 were men (82.47\%) and 112 were women (17.53\%). The rates of death from EC in men increased steadily over the years (Table 1). The standardized mortality rates that used WHO and EU standard populations were higher than the Segi standard. The age-standardized mortality rate (WHO World Standard) in 2013-2014 was 6.32/100,000 which is 2 times higher than in 2005-2006 (3.29/100,000). From 2005 to 2014, the mortality rates in women with EC were always less than 1.00/100,000 (Segi and WHO standards) and increased slowly, regardless of standard populations. (Figure 2) showed that the mortality rates of people with EC had a steady increase. The mortality rates in men were always higher than in women. In 2013-2014, the mortality rate in women was $0.89 / 100,000$; the rate in men was 6.32/100,000, 7.1 times higher than in women. Compared to the period of 2005-2006, the risk of death from EC was significantly increased in 2013-2014, mortality rate ratio MRR $(95 \% \mathrm{CI})$ was $2.79(1.95,3.99)$, p for trend 0.001, (Table 2). The age-specific rates of EC had an upward trend. The rates were low in age groups under $40(<1.00)$ and increased considerably from 40 years old in all periods. Patients aged 70 or older had the highest mortality rate, increasing from 11.33 in 2005-2006 to 15.37 in 2013-2014; the highest was in 2011-2013 with a rate of 18.01 (Figure 3).

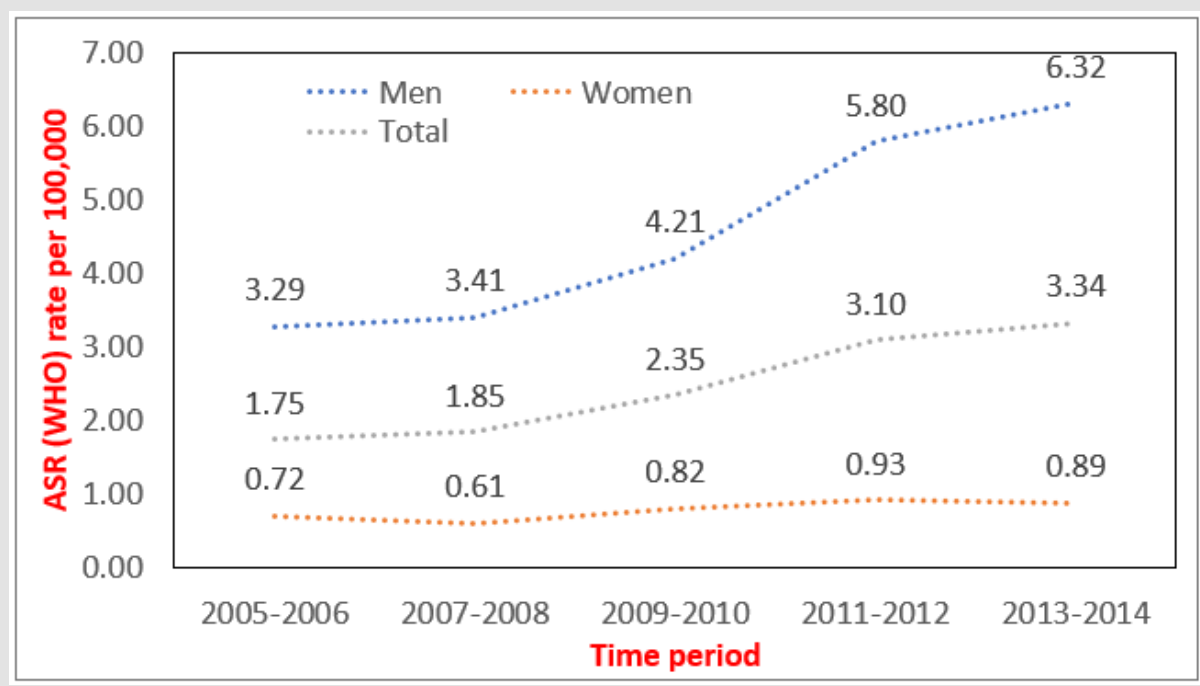

Figure 2: Age-standardized mortality rate per 100,000 by sex and time (WHO world standard).

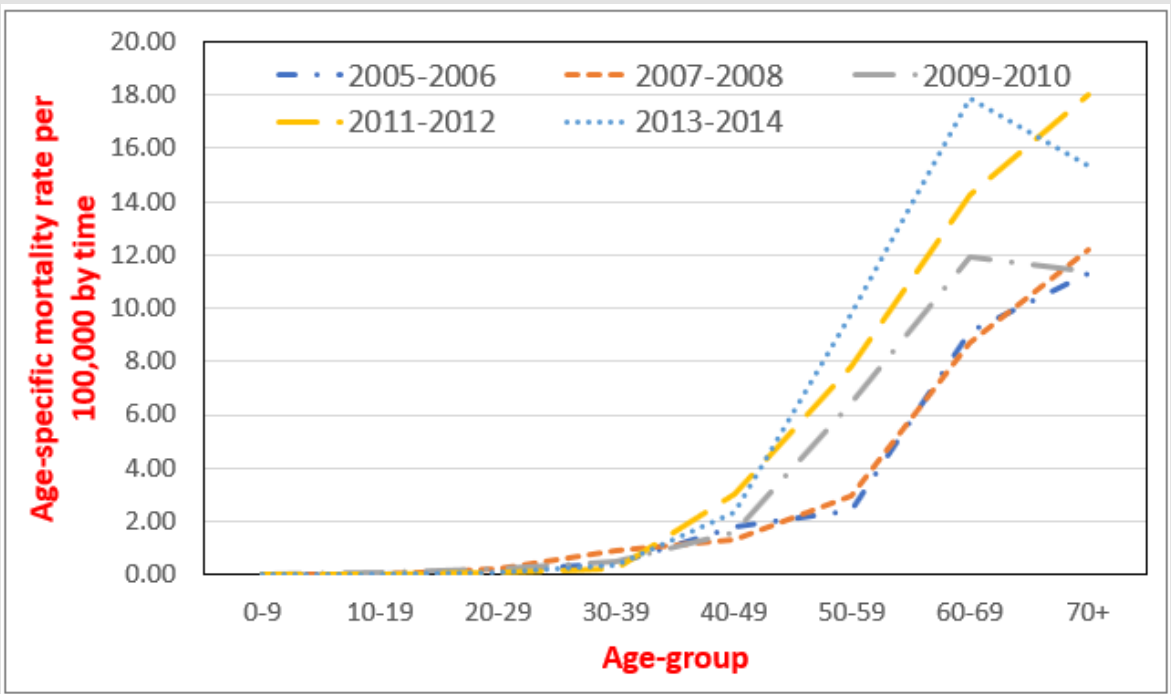

Figure 3: Age-specific mortality rate per 100,000 from the esophagus by time. 
Table 1: Mortality from esophagus during 2005-2014 by sex.

\begin{tabular}{|c|c|c|c|c|c|c|}
\hline \multirow[b]{2}{*}{ Year } & \multirow[b]{2}{*}{ Death } & \multirow[b]{2}{*}{ Percent\# } & \multicolumn{4}{|c|}{ Rate Per 100,000} \\
\hline & & & Crude & Asr & Who & Eu \\
\hline \multicolumn{7}{|c|}{ Men } \\
\hline $2005-2006$ & 65 & 0.5 & 2.6 & 3 & 3.29 & 4.23 \\
\hline $2007-2008$ & 70 & 0.5 & 2.6 & 3.1 & 3.41 & 4.39 \\
\hline $2009-2010$ & 98 & 0.6 & 3.3 & 3.9 & 4.21 & 5.43 \\
\hline 2011-2012 & 140 & 0.8 & 4.5 & 5.3 & 5.8 & 7.52 \\
\hline $2013-2014$ & 154 & 0.8 & 4.9 & 5.8 & 6.32 & 8.21 \\
\hline 2005-2014, total & 527 & 0.6 & 3.67 & 4.29 & 4.7 & 6.08 \\
\hline \multicolumn{7}{|c|}{ Women } \\
\hline $2005-2006$ & 14 & 0.5 & 0.2 & 0.5 & 0.72 & 0.55 \\
\hline $2007-2008$ & 18 & 0.2 & 0.7 & 0.5 & 0.61 & 0.76 \\
\hline $2009-2010$ & 23 & 0.2 & 0.8 & 0.8 & 0.82 & 1.08 \\
\hline 2011-2012 & 30 & 0.2 & 1 & 0.8 & 0.93 & 1.21 \\
\hline $2013-2014$ & 27 & 0.2 & 0.8 & 0.8 & 0.89 & 1.19 \\
\hline 2005-2014, total & 112 & 0.2 & 0.77 & 0.69 & 0.77 & 1.01 \\
\hline
\end{tabular}

Note: \# Percent against total deaths; ASR: Segi (“world”) standard; EU: Scandinavian ("European") standard; WHO: WHO World

Standard.

\section{Discussion}

We conducted this study in Nghe An province for 10 years to describe the trend of deaths from EC. The results showed that from 2005 to 2014, Nghe An had a total of 639 deaths from EC. With this relatively long time and a large study population, we found a significant increasing trend of EC mortality during the 10 years and over $80 \%$ of EC occurred in men. This study used three standard populations including Segi, WHO, and the EU to calculate the age-standardized mortality rates of EC for further comparison of the present study findings with other populations worldwide. The results showed that the mortality rates calculated by using 3 standard populations were different. In all periods, agespecific rates calculated by using the EU standard were the highest compared to Segi and WHO standards. [10]. The mortality rate in 2011-2012 (WHO standard) of Nghe An $(3.1 / 100,000)$ was higher than the estimated mortality rate of Viet Nam by GLOBOCAN-2012 in the same period (2012) which was 2.9/100,000; however, the rate of Nghe An in 10 years $(2.31 / 100,000)$ was lower [11]. From 2005-2014, the age-standardized mortality rate of EC in Nghe An province increased from 1.75/100,000 (2005-2006) to 3.34/100,000 (2013-2014).

Data from GLOBOCAN 2008 and 2012 showed that the mortality rate of EC in Asia declined from 5.8/100,000 to 5.00/100,000. However, more than $75 \%$ of deaths from EC were Asian and occurred mostly in developing countries $[1,12,13]$. This may be due to some recognized risk factors that induce EC: smoking, alcohol consumption, obesity, low intake of vegetables and fruits, and inefficient facilities to implement cancer control programs by annual screening for EC [4,5,11,14]. Furthermore, 36\% of Asians also had an alcohol flushing reaction, which is caused by a deficiency of aldehyde dehydrogenase 2 (ALDH2). People who had ALDH2 heterozygotes and were heavy drinkers had an increased risk of EC [15]. The 5-year relative survival rate of EC is low, ranging from 4 to $40 \%$ depending on the stages of cancer at the time of diagnosis. The 5 -year survival rate was below $20 \%$, suggesting the importance of cancer prevention. However, in Viet Nam, the national screening programs for EC in particular and gastrointestinal cancers, in general, were rarely conducted [3]. In addition, the Vietnamese population is shifting from a young population structure to an aging population and the reporting system of the preventive healthcare system is improving. All of these reasons could partially explain the increased mortality rate of EC in Nghe An province during the study time. Mortality from EC was related to age with the highest rate being in the elderly group. In Nghe An, deaths from EC started to increase rapidly in people aged 40 and higher.

The age group over-70 had the highest mortality rate (Figure 2). This result is similar to other studies in the world. Mortality rates of EC in the UK started to increase rapidly in the age group 45-49 and the highest mortality rate was reported in the age group 89-90 [16]; in the United States, the results were 50-55 years old and $70-80$ years old, respectively $[17,18]$. In this study, $82.47 \%$ of EC deaths were men. This result is similar to WHO estimation of Viet Nam's mortality from EC in 2012: 88\% were men and 12\% 
were women [11]. In Nghe An, the age-standardized mortality rates in men were higher than in women. The results were similar to data from GLOBOCAN 2008 and 2012. Rates of death from EC were higher in men than in women and increased in both sexes in four years: men increased from $8.6 / 100,000$ to $9.9 / 100,000$, women increased from $3.4 / 100,000$ to $3.8 / 100,000[12,13]$. Our results also showed that in women, during the 10 years, the rate increased slightly and was less than $1 / 100,000$ (Table 2). In men, the rate Table 2: Mortality from esophagus during 2005-2014. doubled from 2005 to 2014 (Table 1). This result is similar to the estimated age-standardized mortality rate of Viet Nam in 2012 which reported the rate in men was 5.5 and in women was 0.6 [11]. In 2012, the mortality rate of men with EC in Nghe An was lower than the data of Asia (9.9/100,000) but higher than Southeast Asia $(3.3 / 100,000)[1,11]$. The main reason could be the higher rates of alcohol consumption and smoking among men compared to women $[19,20]$.

\begin{tabular}{|c|c|c|}
\hline Year & Death & MRR (95\% CI) \$ \\
\hline $2005-2006$ & 79 & $1.00($ reference) \\
\hline $2007-2008$ & 88 & $1.21(0.88,1.66)$ \\
\hline $2009-2010$ & 121 & $1.68(1.21,2.33)$ \\
\hline $2011-2012$ & 170 & $2.44(1.70,3.48)$ \\
\hline $2013-2014$ & 181 & $2.79(1.95,3.99)$ \\
\hline P for trend & & 0.001 \\
\hline
\end{tabular}

Note: \$ Adjusted for sex, age, the proportion of unknown underlying cause of death and all-cause mortality rates.

Alcohol and tobacco were shown to be risk factors of EC [21,22]. In Viet Nam, the alcohol consumption per capita per year was estimated to increase from 4.7 liters in 2010 to 8.3 liters in 2016. Alcohol consumption in men was 7 times higher than in women $[19,23]$. The rate of people with harmful alcohol consumption in men (44.2\%) was 40 times higher than in women (1.2\%) [19]. According to GATS 2015, the proportion of men smokers in Viet Nam was $45.3 \%$ but only $1.1 \%$ in women [20]. The higher risk of death from EC in men than in women could be explained partially due to a high prevalence of men smokers in Viet Nam. From January 1, 2020, the Government's Decree No. 100/2019/ND-CP on administrative penalties for road traffic and rail transport violations, and the Law on Prevention and Control of the harms of alcohol and beer abuse took effect which may contribute to reducing alcohol and beer consumption of Vietnamese people in the future, therefore, EC mortality in men will be decreased. Longitudinal studies are needed to evaluate the impacts on alcohol-related cancer cases including EC cases in Viet Nam [24,25].

\section{Conclusion}

Mortality from EC in Nghe An increased significantly over the years with MRR (95\% CI) being 2.79 (1.95, 3.99). In 2013-2014, the rate was $6.32 / 100,000$ which was doubled from 2005-2006 $(3.29 / 100,000)$. The mortality rate began to rise rapidly at the age of 40 with the highest in the age group over 70 . Men had higher mortality rates than women. An annual screening program for EC in men from 40 years old for the high-risk group to detect early EC for treatment at the early stage is highly recommended.

\section{Conflict of Interest Disclosures}

None reported.

\section{Funding/Support}

This study has no support grant.

\section{References}

1. World Health Organization Global cancer observatory 2018: Osephagus 2019. International Agency for Research on Cancer.

2. Bray F, Jacques Ferlay, Isabelle Soerjomataram, Rebecca L Siegel, Lindsey A Torre, et al. (2018) Global cancer statistics 2018: GLOBOCAN estimates of incidence and mortality worldwide for 36 cancers in 185 countries. CA Cancer J Clin 68(6): 394-424.

3. (2017) Cancer facts \& figures 2017. American Cancer Society.

4. Yousefi M S, Mehran Sharifi Esfahani, Nima Pourgholam Amiji, Mohammad Afshar, Hamidreza Sadeghi Gandomani, et al. (2018) Esophageal cancer in the world: incidence, mortality and risk factors. Biomedical Research and Therapy 5(7): 2504-2517.

5. Huang F L, SJ Yu, (2018) Esophageal cancer: Risk factors, genetic association, and treatment. Asian Journal of Surgery 41(3): 210-215.

6. (2018) World Health Organization, Health statistics, and information systems. Disease burden and mortality estimates.

7. (2018) World Health Organization Noncommunicable diseases country profiles 2018.

8. World Health Organization, Global cancer observatory 2018. Country profile: Viet Nam. 2019, International Agency for Research on Cancer.

9. (2017) Freddie Bray and Jacques Ferlay. CHAPTER 7: Age standardization. Cancer Incidence in five continents volume XI.

10. Ahmad O, Cynthia Boschi Pinto, AD Lopez (2001) Age Standardization of rates: A new WHO standard, in GPE Discussion Paper Series: No.31 GPE World Health Organization. 
11. Pakzad R, Abdollah Mohammadian Hafshejani, Bahman Khosravi, Shahin Soltani, Iraj Pakzad, et al. (2016) The incidence and mortality of esophageal cancer and their relationship to development in Asia. Annals of Translational Medicine 4(2).

12. Ferlay J, Hai-Rim Shin, Freddie Bray, David Forman, Colin Mathers, et al. (2010) Estimates of worldwide burden of cancer in 2008: GLOBOCAN 2008. Int J Cancer 127(12): 2893-917.

13. Malhotra G K, Ujwal Yanala, Advaitaa Ravipati, Matthew Follet, M Vijayakumar, et al. (2017) Global trends in esophageal cancer. Journal of Surgical Oncology115(5): 564-579.

14. Fang P, Shunchang Jiao, Xin Zhang, Zhefeng Liu, Hongzhen Wang, et al. (2011) Meta-analysis of ALDH2 variants and esophageal cancer in Asians. Asian Pac J Cancer Prev 12(10): 2623-7.

15. Brooks P J, Mary-Anne Enoch, David Goldman, Ting-Kai Li, Akira Yokoyama (2009) The alcohol flushing response: an unrecognized risk factor for esophageal cancer from alcohol consumption. PLoS Med 6(3): e50.

16. (2019) Cancer Research UK Oesophageal cancer mortality statistics.

17. (2019) New York State. Esophageal Cancer Incidence and Mortality by Age group, New York State Excel New York City, 2012-2016.

ISSN: 2574-1241

DOI: $10.26717 /$ BJSTR.2022.40.006524

Kim Cat Tuyen Vo. Biomed J Sci \& Tech Res

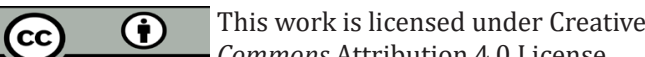

Submission Link: https://biomedres.us/submit-manuscript.php
18. Mathieu L N, N F Kanarek, H-L Tsai, C M Rudin, M V Brock (2014) Age and sex differences in the incidence of esophageal adenocarcinoma: results from the Surveillance, Epidemiology, and End Results (SEER) Registry (1973-2008). Dis Esophagus 27(8): 757-63.

19. Ministry of Health (2016) National survey on the risk factors of noncommunicable diseases (STEPS) Viet Nam 2015.

20. Ministry of Health, et al. (2016) Global Adults Tobacco Survey Viet Nam 2015

21. Mahboubeh Sadat Yousefi, Mehran Sharifi Esfahani, Nima Pourgholam Amiji, Mohammad Afshar, Hamidreza Sadeghi Gandomani, et al. (2018) Esophageal cancer in the world: incidence, mortality, and risk factors. Biomedical Research and Therapy 5(7)

22. Zhang Y (2013) Epidemiology of esophageal cancer. World Journal of Gastroenterology 19(34): 5598

23. (2018) World Health Organization. Alcohol consumption: Levels and patterns. Country profile: Viet Nam.

24. (2019) Government. Decree No. 100/2019/ND-CP on administrative sanctions for road traffic and rail transport violations.

25. (2019) Viet Nam National Assembly, Law on Prevention and Control of Harms of Alcohol and Beer Abuse.

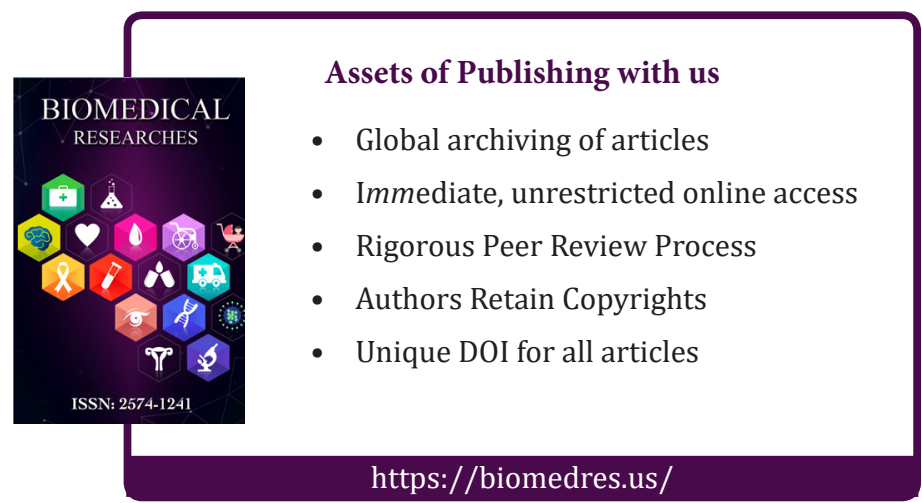

